This item was submitted to Loughborough's Research Repository by the author.

Items in Figshare are protected by copyright, with all rights reserved, unless otherwise indicated.

\title{
Impact of cultural dynamics on conservation of Suakin, Sudan
}

PLEASE CITE THE PUBLISHED VERSION

http://dx.doi.org/10.1680/esu.14.00018

\section{PUBLISHER}

(C) ICE Publishing

\section{VERSION}

VoR (Version of Record)

\section{PUBLISHER STATEMENT}

This work is made available according to the conditions of the Creative Commons Attribution-NonCommercialNoDerivatives 4.0 International (CC BY-NC-ND 4.0) licence. Full details of this licence are available at: https://creativecommons.org/licenses/by-nc-nd/4.0/

\section{LICENCE}

CC BY-NC-ND 4.0

\section{REPOSITORY RECORD}

Ashley, Katherine S., Mohamed Osmani, Stephen Emmitt, Michael Mallinson, and Helen Mallinson. 2019.

"Impact of Cultural Dynamics on Conservation of Suakin, Sudan". figshare. https://hdl.handle.net/2134/17874. 


\section{Impact of cultural dynamics on conservation of Suakin, Sudan}

Katherine Sarah Ashley BA(Hons), Dip, Arch

Part 2 Architectural Assistant and PhD Candidate, Centre for Innovative and Collaborative Construction Engineering, Loughborough University,

Loughborough, UK

Mohamed Osmani BA(Hons), Dip, Arch, MSc, HEA

Senior Lecturer in Architecture and Sustainable Construction,

Loughborough University, Loughborough, UK; Chairman, Construction

Industry Research and Information Association (Ciria) Sustainability Advisory Panel
Stephen Emmitt Dip. Arch., MA, PhD

Professor of Architectural Technology, Loughborough University, Loughborough, UK

Michael Mallinson BA, (Hons), Dip. Arch.

Architect, Mallinson Architects \& Engineers, London, UK

Helen Mallinson Dip. Arch., PhD

Associate, Mallinson Architects \& Engineers, London, UK; Principal Lecturer in Architecture, Sir John Cass Faculty of Art, Architecture and Design, London Metropolitan University, London, UK

The aim of this work was to explore the impact of local cultural dynamics on the conservation of the built heritage of Suakin, an abandoned historic port on the Red Sea coast of Sudan, through a collaborative stakeholder approach. Key representatives of local stakeholder groups attended a two-day workshop and took part in a series of collaborative activities. These encompassed the production of a rank-ordered list of the key local cultural dynamics impacting on the port's conservation, agreement to a number of actions to address obstacles to conservation, identification of local cultural values collectively determined by stakeholder and confirmation of the value of an integrated conservation approach. The workshop enabled a shared understanding and responsibility between stakeholders and established a commitment to further action to address the key local cultural dynamics impacting on the conservation. This collaborative stakeholder participation represented a new step in the port's conservation and invited the development of more formal protocols to enable the equal representation and participation of stakeholders in future conservation activities and initiatives.

\section{Introduction}

Built cultural heritage, such as monuments and historic urban areas, is regarded as an economic, political and socio-cultural resource, and is invested with various values by those seeking to expand it in different ways (Henderson, 2008; Orbasli, 2008; Roders and van Oers, 2011; Rypkema, 2008). Accordingly, conservation philosophy today advocates a values-based approach that determines the significance of a cultural heritage site and its subsequent conservation (Orbasli, 2008). The common definition of conservation is that termed by the International Council of Monuments and Sites (Icomos) in the 1999 Burra charter as 'all the processes of looking after a place so as to retain its cultural significance' (Icomos, 2000).

For built cultural heritage to qualify as World Heritage, it must have 'outstanding universal value' (Jokilehto, 2006; Unesco, 1972). The concept of 'value' in this context refers to a social association of qualities to things, and that is produced through cultural-social processes. After qualifying for outstanding universal value, the heritage is conserved through processes by which the outstanding universal value of the property is protected and consideration is given to heritage resources in both global and local contexts (Rössler, 2010).
The need for conservation initiatives to address both global and local contexts is recognised throughout conservation legislation and research. This is demonstrated by a defined shift from a primarily monumental and aesthetic appreciation of heritage as isolated objects from Unesco's 1972 World Heritage convention (Unesco, 1972) to 'inhabited historic towns' as described in Unesco's operational guidelines (Unesco, 2008). Emphasising this shift is the World Heritage convention's inclusion of 'community' in 2007 as a key strategic objective for implementation; this was intended to ensure participation of local community stakeholders in the identification, nomination and protection of their heritage (Rössler, 2010). As Jokilehto (2006) argues, the concept of universal value can be seen in the 'authentic' expression of a specific or rather local culture, in addition to the physical and historical characteristics of a heritage. Supporting this argument is the view of Henderson (2008), that feelings of authenticity about heritage sites that are living and working communities emerge as critical to both residents and visitors, and that people are increasingly likely to recognise and reject the 'fake' and contrived. Heritage values ought thus to be generated by/within local cultures and to therefore enable the heritage and subsequent conservation initiatives to become an integral part of the local culture (Jokilehto, 2006; Lamei, 2005). 
Engineering Sustainability

Volume 167 Issue ES6
Impact of cultural dynamics on

conservation of Suakin, Sudan

Ashley, Osmani, Emmitt, Mallinson

and Mallinson
While the need to include local stakeholders and integrate local values and conditions within conservation initiatives has been recognised in previous research (Chapagain, 2008; Chirikure et al., 2010; Daher, 2005), there is little evidence of this effectively translating to conservation practice. Many local stakeholders and conditions are not understood within formal governmentdriven conservation initiatives and policies (Chapagain, 2008; Hill, 2011; Nasser, 2003; Zancheti and Kulikauskas, 2007). The numerous international parties that influence conservation legislation, such as international charters, are argued to result in a conventional universal conservation approach that neglects the local socio-cultural dynamics of a specific site (Chapagain, 2008; Jokilehto, 2011). Consequently, a distinct contrast has emerged between the legislative sense of values, the local sense of values and what is implemented in conservation practice (Orbasli, 2008). Factors that contribute towards the disparity between legislative and local levels include

the rapidly evolving context of historic urban areas that results in local cultural values being in a constant state of flux and needing to be engaged in the conservation process on an ongoing basis (Araoz, 2011; Henderson, 2008), yet often prevented by the static nature of internationally determined conservation

- the low financial and technical capacity of many communities, especially within developing regions, which renders the recognition and conservation of a local heritage to be even more vulnerable to the dominance of international forces (Breen, 2007; Saouma-Forero, 2006).

To redress the imbalance between legislative and local levels in the conservation of built heritage, a call has been made for a collaborative goal-orientated approach that engages the stakeholders involved (Bott et al., 2011; Fahmi and Sutton, 2010; Zancheti and Hidaka, 2011). This enables stakeholders to enjoy a greater degree of consensus and a sense of ownership over their heritage and its safeguarding, which is recognised as a key requirement by international conservation policy makers and the donor community (Araoz, 2011; Chirikure et al., 2010). To achieve this approach, stakeholders need to first share their intentions towards the actions that need to take place (Lisitzin, 2005). However, a clear differentiation can be made between those 'shared intentions' derived from individual initiatives (but commonly shared) and those derived from collective actions and commitment (Gilbert, 2009). It can be argued that collectively derived shared intentions underwrite collaborative activity and a shared responsibility towards a common goal (Grosz and Hunsberger, 2006; Perkin, 2010; Tomasello and Carpenter, 2007). To help generate shared intentions, effective communication and understanding needs to be facilitated between stakeholders to convince all parties of the merits of working together (Bott et al., 2011; Grimwade and Carter, 2000; Zancheti and Hidaka, 2011). Enabling such mutual exchange between all stakeholders is essential to enable a more relevant bottom-up approach that respects the values and true needs of existing communities and places, rather than top-down confrontational approaches that impose a more restricted set of pre-determined ideas and criteria (Jokilehto, 2011; Lamei, 2005; Rypkema, 2008). Yet, as Aas et al. (2005) argue, a lack of communicative methods is a major challenge that prevents essential understanding and subsequent collaboration and responsibility among conservation stakeholders, and must therefore be investigated further.

This paper details research undertaken to explore the impact of local cultural dynamics on the conservation of the built heritage of Suakin, an abandoned historic port on the Red Sea coast, through initiation of a collaborative stakeholder approach.

\section{Context}

Suakin was once Sudan's major port and one of the largest ports on the Red Sea, and still provides the gateway between eastern Africa and Jeddah on the pilgrimage route to Mecca (Figure 1). Yet despite Suakin's historic and cultural significance, the old town is increasingly threatened. Physical deterioration ensued as the historic coral block buildings were largely abandoned following the opening of Sudan's new Port Sudan in 1909 (Figure 2) and development pressures were introduced following the opening of Suakin's new Osman Digna Port in 1991 (Salim, 1997) (Figure 3).

Numerous studies and proposals for Suakin's conservation and revival have been produced, including surveys, a number of formal Unesco reports and an application for World Heritage status (Greenlaw, 1995; Hansen, 1973; Lane, 1994; Mallinson, 2012). However, many of these proposals have not materialised on the ground due to a number of financial restrictions such as limited government resources (Salim, 1997) and difficulties in obtaining available funds for conservation initiatives as opposed to Sudan's more immediate needs (Hansen, 1973). Legal restrictions have formed the other major challenge to Suakin's conservation - private ownership of historic properties has prevented government-led interventions and restrictive government legislation has prevented privately led interventions. Suakin has thus remained on the World Heritage tentative list since 1994 without full status being gained (Mallinson, 2012). While the majority of previous research has focused on the historic and/or physical environment (Greenlaw, 1995; Hansen, 1973; Lane, 1994), two examples also attempted to address Suakin's conservation in relation to its socio-cultural and economic context.

The first example is a proposal made by Salim (1997), which identified the major challenges preventing Suakin's conservation as finances, ownership and lack of active involvement of 
Impact of cultural dynamics on

conservation of Suakin, Sudan

Ashley, Osmani, Emmitt, Mallinson and Mallinson

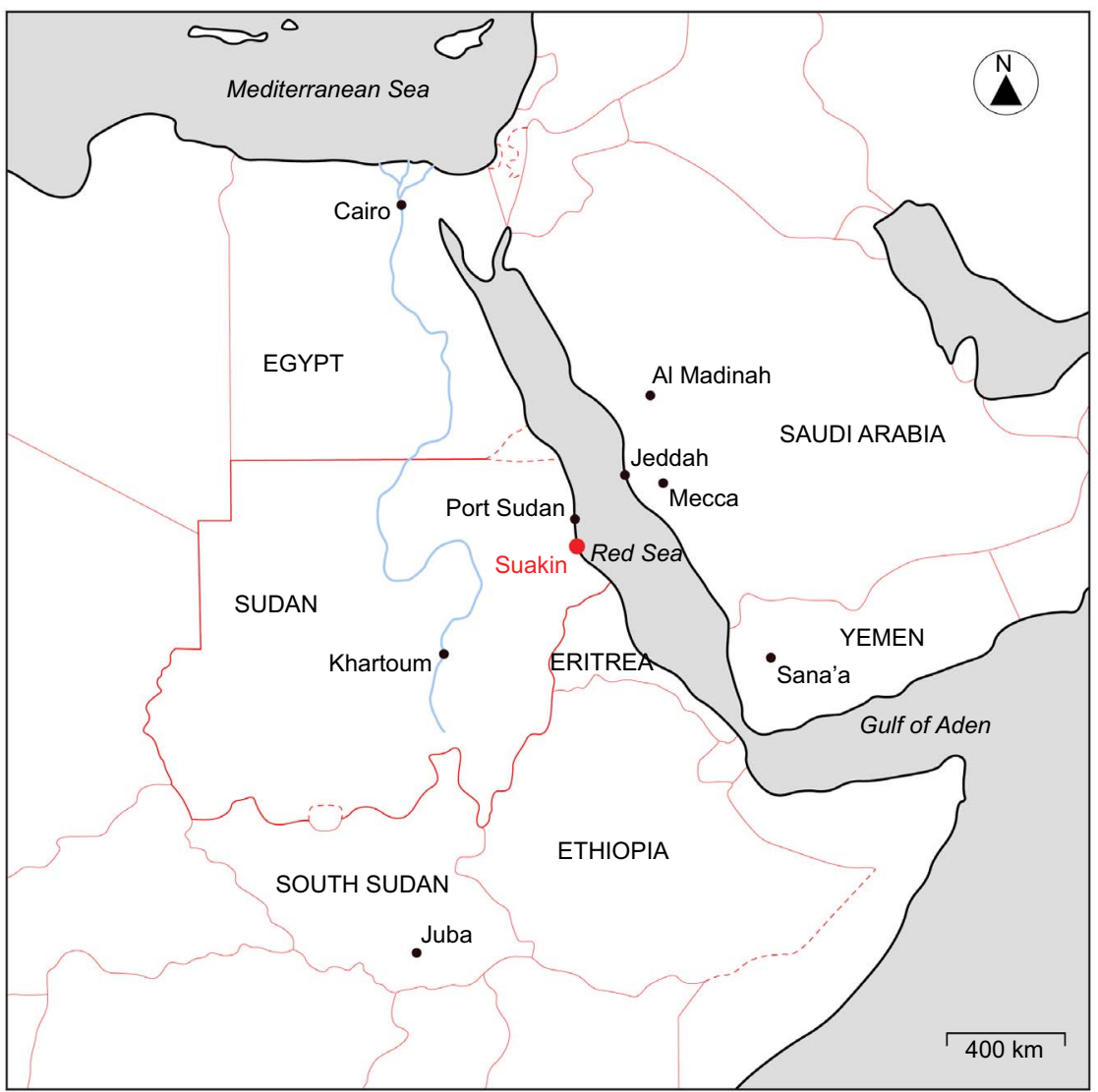

Figure 1. Location of Suakin

both government and non-government parties. National and local stakeholder committees were formed and international involvement was sought from foreign governments and organisations such as Unesco. Salim (1997) suggested the

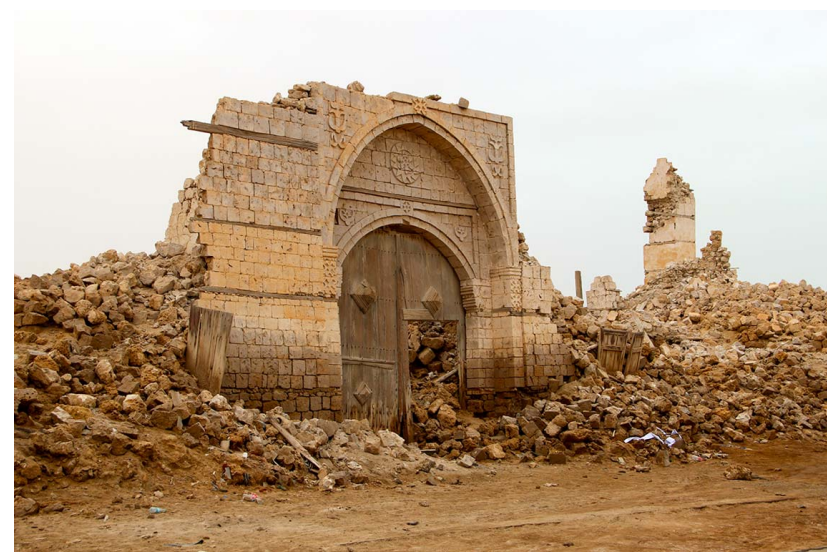

Figure 2. Deterioration of Suakin's historic coral block buildings development of an initial action plan and a master plan for Suakin, to include

identification of resources

- reconstruction and development priorities

- resolution of reconstruction and development obstacles

- roles and relationships of the stakeholders concerning Suakin's reconstruction and development

- reconstruction and development guidelines

future prospects and viability of the proposal.

The second attempt, in 2007, was by Sudan's National Corporation for Antiquities and Museums (NCAM), funded through Unesco, to address the future of NCAM's Suakin development plan (SDP) and recognition of Suakin's cultural heritage (NCAM, 2007). The SDP was developed by NCAM in 2007 for historic Suakin's conservation and sustainable development of the surrounding new town. A range of Suakin's stakeholders participated in a workshop and a number of conservation-related parameters were identified concerning the future of the SDP and Suakin's cultural heritage, including 
Engineering Sustainability

Volume 167 Issue ES6
Impact of cultural dynamics on

conservation of Suakin, Sudan

Ashley, Osmani, Emmitt, Mallinson

and Mallinson

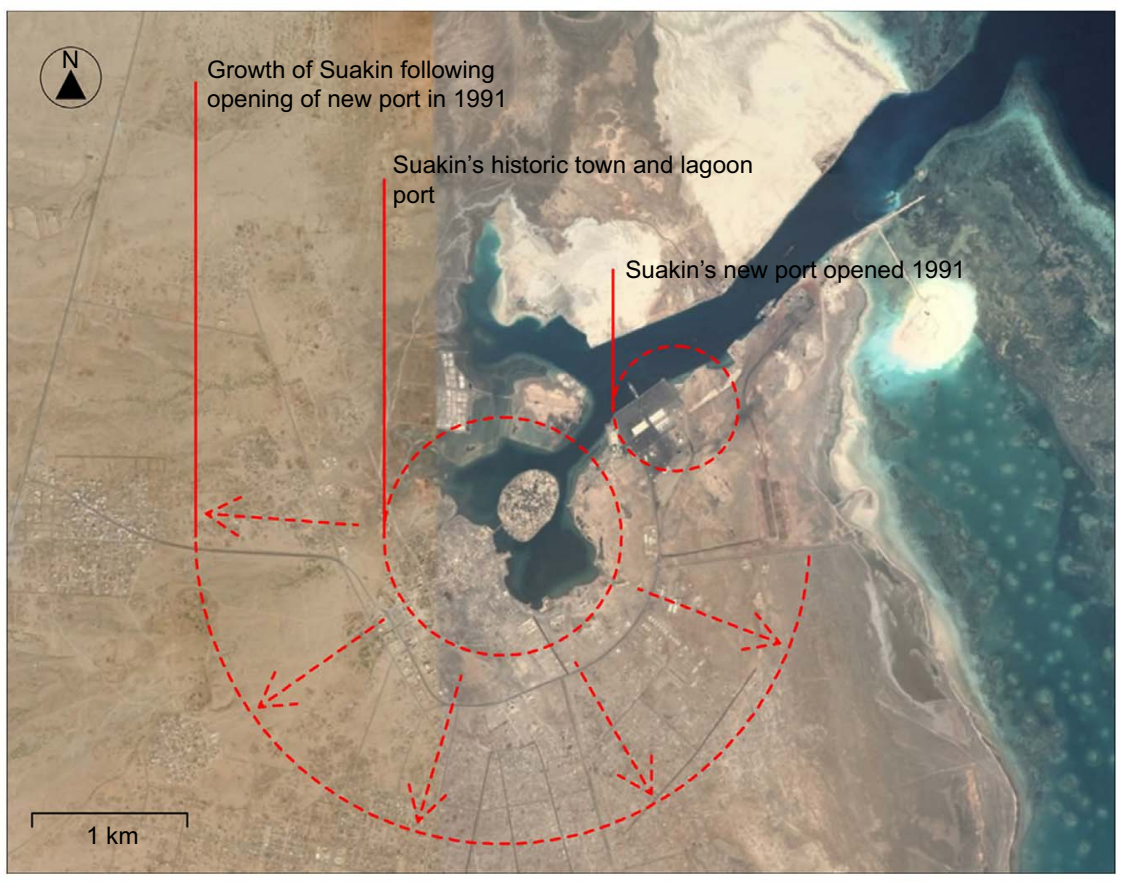

Figure 3. Growth of Suakin town following opening of new Suakin port in 1991 (adapted from Google Earth)

Suakin's cultural value

- Suakin's conservation and development drivers

ownership as the major obstacle to be addressed

- suggested restorations and reconstructions

- the over-arching consensus that the revival of 'life' within Suakin's abandoned historic town was essential to its restoration and reconstruction (NCAM, 2007).

Both Salim's proposal and the NCAM initiative identified a number of actions supposedly needed for the reconstruction of historic Suakin and the development of the surrounding new town. Both endeavours recognised Suakin's stakeholders and began to involve them in efforts towards Suakin's conservation, yet there is no evidence of follow-up actions from either study. Hence, the work described here adopted participatory action research (PAR; http://participaction.wordpress.com) to enable Suakin's stakeholders to collectively explore the impact of local cultural dynamics on the conservation of their built heritage and to establish a shared intention and responsibility towards this goal.

\section{Method}

To explore the impact of local cultural dynamics on the conservation of Suakin's built heritage, an ethnographic approach and PAR was conducted through a two-day workshop event. The workshop, facilitated by the lead author, involved a series of collaborative activities and discussion among Suakin's stakeholder participants. The first day of the workshop involved the stakeholders ranking the local cultural dynamics that impact on Suakin's conservation and determining a number of actions to address these issues. The second day focused on stakeholders' identification of Suakin's cultural values and the plenary session.

\subsection{Participatory action research}

This research sought to address the local cultural dynamics impacting on Suakin's conservation through a collaborative stakeholder approach. There was no previous evidence of such an approach, and methods to achieve this, conducted within the specific context of Suakin. Consequently, a review of available research methods was conducted. Methods that involved the stakeholders on an individual basis (e.g. interviews and questionnaires) did not facilitate the representation and collaborative participation of Suakin's stakeholder groups required for this research. Participatory action research (PAR) - an umbrella term for a variety of participatory approaches to action-orientated research (Kindon et al., 2007) - did, however, enable the researcher and participants to work together collectively to examine the issues under investigation (Bergold and Thomas, 2012; Dover, 2008; McIntyre, 2008; Pain et al., 2012; Predota, 2009; Wadsworth, 1998). Through such collaborative activity, PAR had the major advantage over other research methods of 
Engineering Sustainability

Volume 167 Issue ES6
Impact of cultural dynamics on

conservation of Suakin, Sudan

Ashley, Osmani, Emmitt, Mallinson

and Mallinson generating shared ownership of the research project by the researcher and the participants (Denzin, 2000). This was critical to establish a shared understanding among Suakin's conservation stakeholders and a collective responsibility towards further action.

Similar to the local cultural dynamics addressed through this research, previous studies have conducted PAR through participant workshops to address varying stakeholders' perspectives. For example, workshops have been used to facilitate instruction, activity and discussion, and subsequently established effective dialogue between stakeholders to reach a common ground (Borg et al., 2012; Silverman et al., 2008). The major benefits of such an approach are the ability to design a carefully structured and reflexive process and to enable stakeholders to have profound influence on both strategic and delivery levels of the research being conducted (Borg et al., 2012). Therefore, PAR was conducted through workshop activities for this research to enable the inclusion of stakeholders, as both participant researchers and research subjects, to collaboratively address the local cultural dynamics impacting on Suakin's conservation.

\subsection{Sampling frame}

Suakin's major stakeholder groups and representative workshop participants were identified through discussions with those involved in previous research (NCAM, 2007; Salim, 1997). They were selected according to their previous, current or potential/future roles in Suakin's conservation (Table 1). To conduct the workshop activities, the participants were organised into stakeholder groups (government, investors, consultants and end users).

\subsection{Workshop design and activities}

The aim of the workshop was to explore the impact of local cultural dynamics on the conservation of Suakin's built heritage. The major local cultural dynamics impacting Suakin's conservation identified through previous research (Hansen, 1973; Lane, 1994; NCAM, 2007; Salim, 1997) were the focus of the workshop design. The local cultural dynamics were
financial restrictions (FR)
ownership (O)
- stakeholder inclusion and collaboration (SIC)
political and legislative support (PLS)
- response to the local context (RLC)
conservation knowledge and awareness (CKA).

The workshop activities were carefully structured and sequenced according to the recurrent stages of action and reflection within PAR (Pain et al., 2012) to enable the stakeholders to collectively, within their groups, address the issues under investigation (Figure 4). An exhibition, provided by the lead author throughout the workshop, explained the context of Suakin's historical and cultural significance and proposed conservation (Figure 5). An introductory presentation outlined the workshop background concerning the conservation of Suakin's built heritage. The workshop aims, activities and expected outcomes were then explained. These included

the stakeholders' individual and then collective group ranking of the local cultural dynamics impacting Suakin's conservation (activity 1)

collective determination of a number of actions to address these dynamics (activity 2)

- collective identification of Suakin's cultural values (activity 3)

plenary session.

Activity templates were completed by the stakeholder participants individually (activity 1) and collectively within their stakeholder groups (activities 1, 2 and 3) (Figure 6).

Activity 1 provided a background explanation for each major local cultural dynamic impacting Suakin's conservation.

- Financial restrictions (FR) concerned limited financial resources at government and local levels, the need for a fundraising strategy to address this issue and the long-term feasibility of potential investment.

Ownership (O) involved conflicts between the owners themselves and the government's restriction by owners and the owners' restriction by the government to implement conservation and/or development efforts within historic Suakin.

- Stakeholder inclusion and collaboration (SIC) consisted of a lack of collaboration due to divergences between stakeholders' interests and operations, and the need for increased local involvement.

- Political and legislative support (PLS) was explained as involving a removal between the interest and understanding of 'top' governmental and policy-making levels, and 'bottom' local levels, and a reliance on top-down conservation approaches, policies and strategies towards Suakin's conservation.

- Response to the local context (RLC) involved the local community often neglected by, and not included within, conservation efforts.

Conservation knowledge and awareness (CKA) concerned an inadequate awareness of conservation-related issues at both local and decision-making levels.

The stakeholders were asked to, first individually and then collectively within their groups, rank these dynamics in order of importance to be addressed and to carefully consider and discuss their justification for these rankings. Following completion of the activity 1 templates, a representative from 


\section{Government (G) stakeholder group}

Federal government party: Sudan's NCAM responsible for Suakin as an antiquities site and the SDP

Red Sea state government: authority for the state in which Suakin is located; partners with and directs/influences government and foreign investment efforts within Suakin and the surrounding area

Local authorities: part of the state government; close relationship with and influence over the local community and their support towards conservation and development initiatives

Investors (I) stakeholder group

State government ministry of physical planning and development: responsible for development (and conservation) initiatives within Suakin and the surrounding area; directs state funds towards specific developments/ initiatives

Foreign research parties: have funded, and intend to fund, research efforts that contribute to Suakin's future conservation and previous restoration of Suakin's historic structures

Educational parties: educational groups regularly visit the site, potentially influencing future investment towards the site's conservation and establishment as an educational resource

International development parties: current and future funding of new developments within Suakin's historic town and surrounding area that directly impact the historic town as a 'cultural heritage' site; previous funding of missions towards Suakin's conservation as a cultural heritage; potential investment towards Suakin's conservation as a cultural heritage

Local industries: representing current local context that must be responded to by conservation and development efforts; currently influencing development and growth within the historic town and surrounding area, directly impacting the conservation of the historic site; potential to attract and direct funding towards the site's conservation and new development efforts that would support the site's conservation

Table 1. Workshop stakeholder groups and participants (continued on next page)
G1 Head of conservation

G5 Senior inspector for archaeology (previously director of NCAM's Suakin office)

G2 Ministry of Culture department manager

G3 Manager, Ministry of Tourism

G4 Suakin Commissioner representative

G6 General director of government and civil service (and local Beja tribe representative)

$12 \quad$ Director and architect

I1 Co-director and archaeologist, Suakin archaeology project, Cambridge University (involving excavation and reconstruction efforts)

16 Student, Red Sea University (previously conducted research in Suakin and often visits the site; potential implementation of future research efforts contributing towards Suakin's conservation and attracting funding for Suakin as an educational resource)

I3 Gender consultant, UNIDO (recently funded new

14 Suakin Fisheries building within the historic site; potential to fund future conservation and development efforts)

Retired World Bank employee (and current Suakin Mayor) (although not previously involved in Suakin, the World Bank represents a multi-lateral development agency that could provide access to future funding towards Suakin's conservation)

I5 Fish landing site manager, Suakin Fisheries (involved

17 in recent construction of new Suakin Fisheries building within Suakin's historic town and direct impact of this on the site's conservation status) Port manager, Suakin Port, Sudan Sea Ports Corporation (currently funding new developments throughout Suakin, potential to fund conservation efforts) 
Consultants (C) stakeholder group

National and local consultants: previously involved in direct efforts towards Suakin's conservation; involved in new developments throughout the local area that could potentially impact Suakin's conservation, and/or representing consultants who could become involved with Suakin's conservation Foreign consultants: previously involved in direct efforts towards Suakin's conservation

End users (E) stakeholder group Local landowners and residents: influencing the potential conservation of privately owned properties within historic Suakin; representing current local context that must be responded to by conservation and development efforts; potential to participate within future conservation efforts improving and/or providing their homes and/or local facilities

$\begin{array}{ll}\text { C2 } & \text { Conservator/restorer } \\ \text { C3 } & \text { Architect restorer and urban planner } \\ \text { C4 } & \text { Conservation architect and Suakin Project consultant } \\ \text { C5 } & \text { Architect and town planner } \\ \text { C1 } & \text { Architect and Suakin project consultant } \\ \text { E1 } & \text { Local landowner } \\ \text { E2 } & \text { Local resident and head of Historic Suakin Town } \\ \text { E3 } & \begin{array}{l}\text { Community Committee } \\ \text { Representative of Khatmeya Sufi Sect, a local }\end{array} \\ \text { E4 } & \text { Loligious group } \\ & \text { Socal Beja tribe (nomadic tribes throughout Suakin's } \\ \text { S4 } & \begin{array}{l}\text { Sudan Beja Cultural Centre } \\ \text { Local civil activist }\end{array}\end{array}$

C2 Conservator/restorer

C3 Architect restorer and urban planner

C4 Conservation architect and Suakin Project consultant

Table 1. Continued

each stakeholder group presented their group's results to the rest of the workshop participants.

Activity 2 enabled the stakeholders to collectively (within their groups) determine a number of actions to address their top three ranked local cultural dynamics impacting Suakin's conservation identified during activity 1 . The stakeholders were also asked to include a timescale for implementation of each of these actions as imminent, short, medium or long term. Following completion of the activity 2 templates, a representative from each stakeholder group presented the group results to the other participants.

Activity 3 involved a presentation on cultural heritage 'values' and conservation by a Unesco World Heritage Centre consultant. This provided a background to the concept of 'cultural values' within conservation and encouraged the stakeholders to consider what Suakin's cultural values were to them. This consideration of what they were trying to conserve, and why, was intended to develop a sense of collective motivation among the stakeholders towards implementation of the actions proposed during activity 2 . The stakeholders collectively (within their groups) then identified Suakin's cultural values and listed/ranked them in order of significance (the most significant being listed first). It was explained to the stakeholders that their cultural values for Suakin could be whatever they wished, not selected from a prescribed list. Following completion of the activity 3 templates, a representative from each stakeholder group presented their group's results to the workshop.
A plenary session facilitated by the lead author invited all workshop participants to raise questions or remarks concerning the activities that had been conducted. Quantitative analysis of the completed activity templates determined average rankings of the local cultural dynamics impacting Suakin's conservation by both individual stakeholders and the stakeholder groups. Qualitative analysis of the completed activity templates and observational notes completed throughout the workshop event determined similarities and differences between the stakeholders' responses and over-arching themes among the workshop activities. The activity results and workshop findings are discussed in Section 4.

\subsection{Methodological challenges}

A number of challenges were encountered during the organisation and implementation of the workshop event. Although invited, key political and authoritative stakeholders concerning Suakin's conservation, including the Red Sea state governor and the Sudan Unesco ambassador, were unable to attend the workshop. The necessity for this key political support has already been demonstrated: proposals for Suakin's conservation have been made (NCAM, 2007; Salim, 1997) yet none have been endorsed as legal measures or part of the political agenda and therefore were not implemented. The potential impact of this research was thus not realised as much as it could have been if all key political and authoritative figures had been able to attend the workshop event. That said, the invited stakeholders who were not able to attend the workshop and/or their representatives stated their keen interest in what had been achieved through the research and their enthusiasm to participate in future initiatives. 


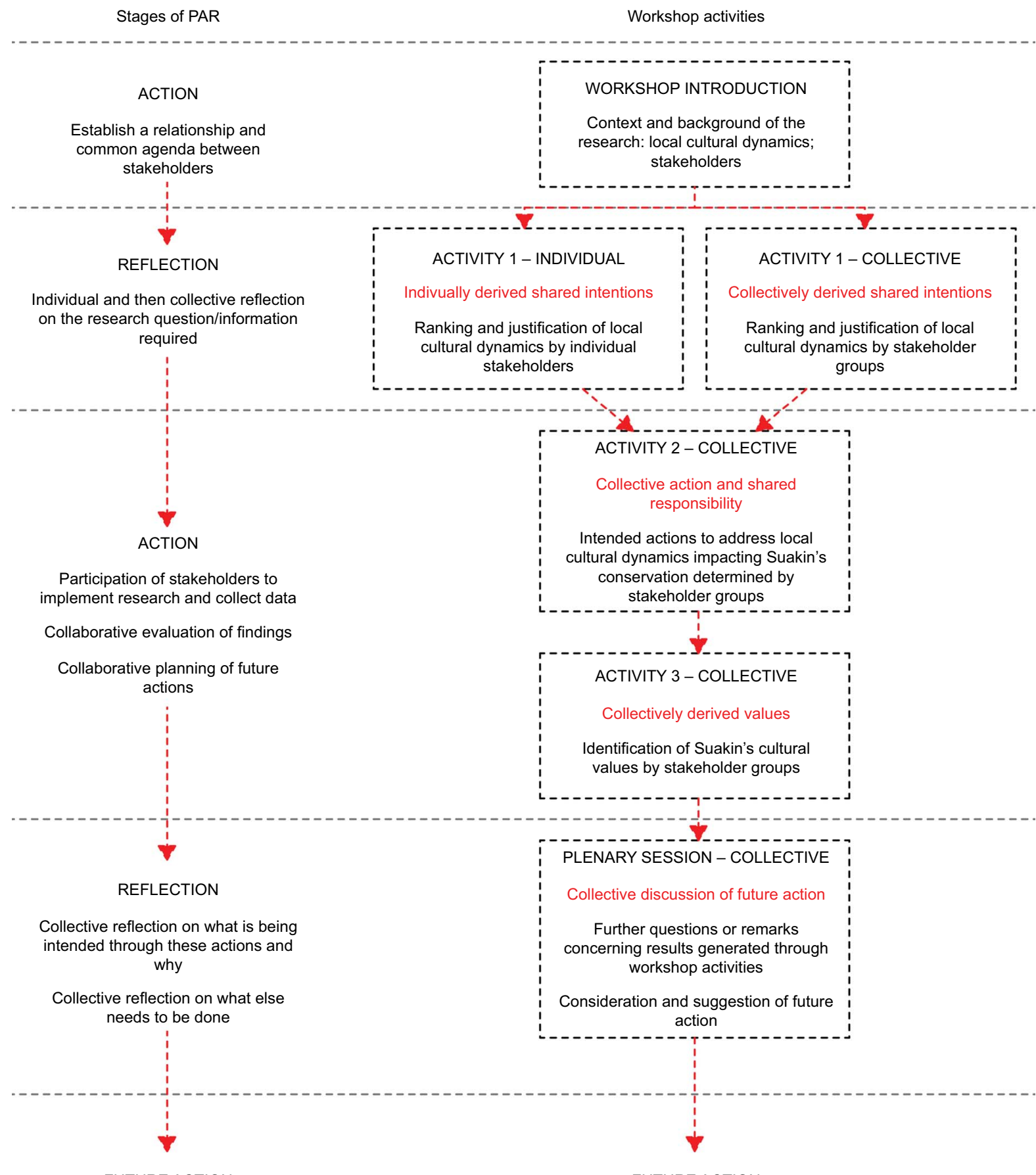

FUTURE ACTION

FUTURE ACTION

Figure 4. Typical stages of PAR and Suakin's workshop activities

Throughout the discussions it was specified that creating greater awareness of Suakin's conservation and longer-term notice of initiatives conducted towards this would encourage greater participation. Recognition by Sudan's government and specialist organisations (e.g. Unesco) of ongoing work towards Suakin's conservation was also suggested as a means to encourage attendance of future events and formal endorsement of outcomes generated. Working towards these suggestions, the Sudan federal government's NCAM has since provided formal recognition of this research. Accordingly, NCAM has agreed to facilitate formal correspondence and invitations to key political and authoritative figures concerning future events associated with this research. 
Impact of cultural dynamics on conservation of Suakin, Sudan Ashley, Osmani, Emmitt, Mallinson and Mallinson

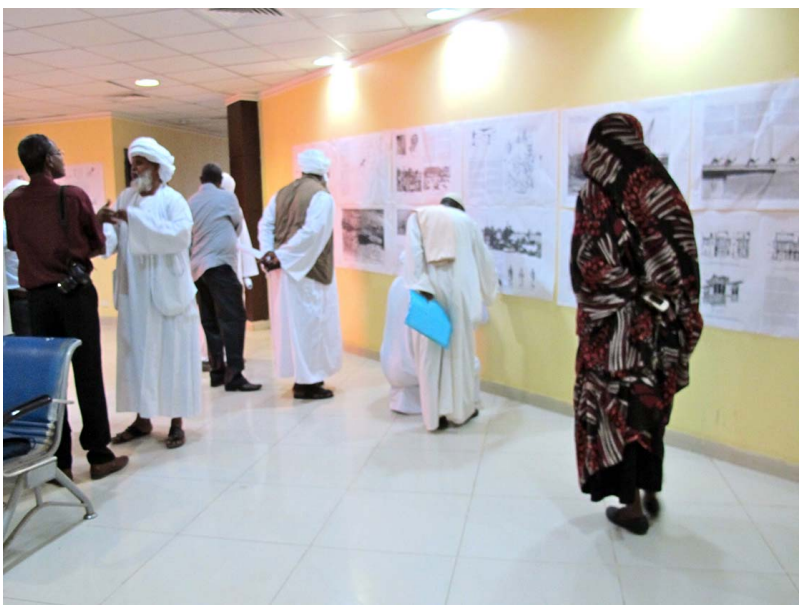

Figure 5. Exhibition set up throughout workshop event on the context of Suakin's historical and cultural significance and proposed conservation

The second major challenge was achieving equal representation (and participation) of Suakin's stakeholder groups within the workshop activities. This was due to an expressed reluctance by some of Suakin's government stakeholders to include local stakeholders in the workshop conducted for this research and future activities. The expressed opinion was that local stakeholders did not and should not have significant input or authority towards Suakin's conservation, as this was considered the responsibility of government stakeholders. This challenge is reinforced by previous research demonstrating that local communities are often marginalised and unable to participate in, initialise or continue conservation programmes (Bergold and Thomas, 2012; Hill, 2011). In addition to the capacity of local stakeholders to participate in the conservation process, Chirikure et al. (2010) question whether conservation actors from these 'top'

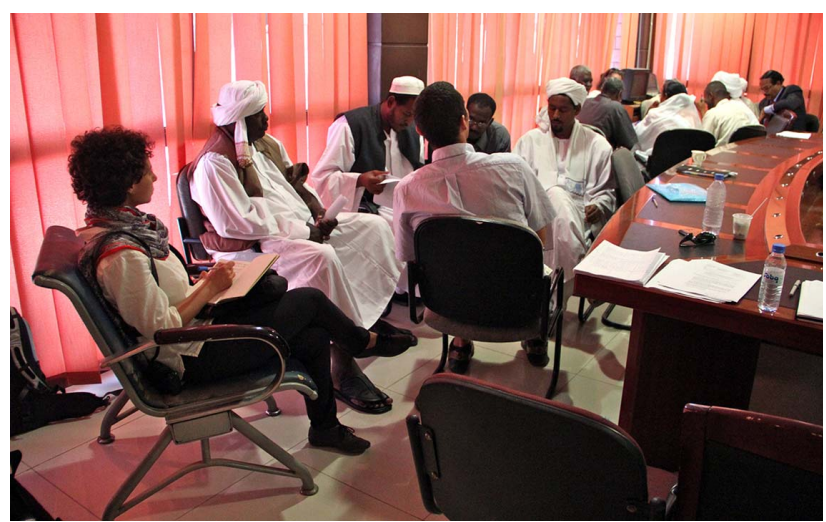

Figure 6. Workshop activity templates being completed collectively by participants within stakeholder groups governmental and management levels are adequately skilled to effectively engage local communities. This challenge was overcome to an extent within this research as efforts by the lead author to facilitate the workshop event ensured that local stakeholders were equally represented. This does, however, question the probability that all Suakin's stakeholder groups, notably local parties, will be equally represented in future conservation initiatives, especially those implemented at government level.

\section{Results and analysis}

\subsection{Activity 1: Ranking of Suakin's local cultural dynamics}

Tables 2 and 3 illustrate the individual stakeholder (Table 2) and stakeholder group (Table 3) rankings of the local cultural dynamics impacting Suakin's conservation completed during activity 1 . The focus of activity 1 was not to highlight and then analyse major differences between the stakeholders' responses - it aimed to encourage the stakeholders to reflect on and rank the local cultural dynamics in order of importance, or urgency to be addressed, in preparation for activity 2 .

Activity 1 revealed the same average top three local cultural dynamics impacting Suakin's conservation generated by both the individual and stakeholder group activities. The top three local cultural dynamics in order of importance, or urgency to be addressed, were ownership (O), financial restrictions (FR) and stakeholder inclusion and collaboration (SIC). The individual stakeholder activities revealed an average ranking of political and legislative support (PLS) as the fourth major dynamic, response to the local context (RLC) as the fifth and conservation knowledge and awareness (CKA) as the sixth. The stakeholder group activities revealed an average ranking of CKA as the fourth major dynamic, RLC as the fifth and PLS as the sixth.

As shown in Tables 2 and 3, there were a number of significant contrasts between the average rankings and the rankings of individual stakeholders and stakeholder groups, demonstrating the specific interests and agendas of the stakeholders and stakeholder groups. For example, the majority of individual investors emphasised the importance (with first or second ranking) of FR and $\mathrm{O}$, as these immediately impact the ability to invest in and implement Suakin's conservation and development efforts. The government's group ranking of SIC was lower than the average stakeholder groups' ranking, as Suakin's conservation is generally conducted at government level and often without the inclusion of other stakeholders considered a necessity.

\subsection{Activity 2: Impact of local cultural dynamics on Suakin's conservation}

Table 4 summarises the proposed actions and timescales determined by each stakeholder group during activity 2 to 


\begin{tabular}{|c|c|c|c|c|c|c|}
\hline \multirow[b]{2}{*}{ Participant code } & \multicolumn{6}{|c|}{ Local cultural dynamic } \\
\hline & FR & $\mathrm{O}$ & $\mathrm{SIC}$ & PLS & RLC & CKA \\
\hline G1 & 3 & 1 & 4 & 5 & 6 & 2 \\
\hline $\mathrm{G} 2$ & 3 & 1 & 4 & 5 & 2 & 6 \\
\hline G3 & 2 & 1 & 5 & 3 & 6 & 4 \\
\hline G4 & 5 & 1 & 4 & 2 & 6 & 3 \\
\hline G5 & 1 & 4 & 5 & 2 & 3 & 6 \\
\hline G6 & 1 & 4 & 5 & 2 & 6 & 3 \\
\hline 11 & 1 & 4 & 6 & 2 & 5 & 3 \\
\hline 12 & 1 & 2 & 4 & 6 & 5 & 3 \\
\hline 13 & 1 & 6 & 2 & 5 & 3 & 4 \\
\hline 14 & 2 & 3 & 1 & 5 & 4 & 6 \\
\hline 15 & 2 & 1 & 4 & 3 & 5 & 6 \\
\hline 16 & 2 & 3 & 1 & 5 & 4 & 6 \\
\hline $\mathrm{C} 1$ & 5 & 3 & 1 & 6 & 4 & 2 \\
\hline $\mathrm{C} 2$ & 1 & 3 & 2 & 4 & 5 & 6 \\
\hline $\mathrm{C} 3$ & 4 & 2 & 3 & 5 & 6 & 1 \\
\hline C4 & 2 & 1 & 3 & 6 & 4 & 5 \\
\hline $\mathrm{C} 5$ & 4 & 1 & 3 & 2 & 1 & 5 \\
\hline E1 & 5 & 1 & 2 & 3 & 4 & 6 \\
\hline E2 & 4 & 5 & 1 & 3 & 2 & 6 \\
\hline E3 & 1 & 4 & 4 & 2 & 3 & 4 \\
\hline E4 & 4 & 3 & 3 & 6 & 5 & 1 \\
\hline E5 & 2 & 3 & 6 & 5 & 1 & 4 \\
\hline Average ranking & 1 & 2 & 3 & 4 & 5 & 6 \\
\hline
\end{tabular}

Table 2. Activity 1: Individual stakeholder rankings of local cultural dynamics impacting Suakin's conservation

address the top three local cultural dynamics ranked by each stakeholder group during activity 1 .

After deducting a number of overlaps, activity 2 resulted in a total of 16 actions determined by the stakeholder groups to address the local cultural dynamics impacting Suakin's conservation. Reflecting the average individual stakeholder and stakeholder group rankings during activity 1 , the major focus of the actions determined during activity 2 addressed $\mathrm{O}, \mathrm{FR}$ and SIC. Subsequently, CKA, RLC and PLS received comparatively

\begin{tabular}{lllllll}
\hline & \multicolumn{5}{l}{ Local cultural dynamic } \\
\cline { 2 - 6 } Stakeholder group & O & FR & SIC & CKA & RLC & PLS \\
\hline Government & 4 & $1+2^{\text {a }}$ & 5 & $1+2^{\text {a }}$ & 6 & 3 \\
Investors & 1 & 2 & 4 & 6 & 3 & 5 \\
Consultants & 1 & 4 & 2 & 6 & 3 & 6 \\
End users & 1 & 2 & 4 & 4 & 5 & 6 \\
Average ranking & 1 & 2 & 3 & & & 5 \\
\hline
\end{tabular}

a $1+2$ : Jointly ranked by the stakeholder group as the joint first and second local cultural dynamics impacting on Suakin's conservation

Table 3. Activity 1: Stakeholder group rankings of local cultural dynamics impacting Suakin's conservation 
$\mathrm{G} \quad \mathrm{O} 1$ - identify property owners to take responsibility and action

G $\quad$ O2 - enable collaboration between property owners and government to overcome 'stalemate' situation between private ownership and legislative restrictions within the historic site

\section{I $\quad 03$ - same as 01}

I $\quad$ O4 - provide government compensation of private land within historic Suakin with larger land areas elsewhere more commercially viable in the short-term; this enables historic Suakin property to be used by government or other public bodies, or re-sold O5 - generate a new local order to permit land registration within historic Suakin under current owners' name, with options for the family to implement construction/ conservation works, to divide the land between the owning family members, or re-sell $\mathrm{O} 6$ - same as $\mathrm{O} 4$

Local cultural dynamic addressed: Financial restrictions (FR)

G $\quad$ FR1 - increase awareness of Suakin's conservation to enable investment in conservation initiatives (through various facilities, events and activities)

I $\quad$ FR2 - same as FR1

I FR3 - provide a contribution from Suakin's port (e.g. toll paid by ships and ferry passengers) towards a conservation fund

C No proposed actions

E $\quad$ FR4 - enable property owners to implement construction to integrate historic Suakin with local economy and therefore generate income towards future/ongoing conservation initiatives

Local cultural dynamic addressed: Stakeholder inclusion and collaboration (SIC)

G No proposed actions

I No proposed actions

C SIC 1 - facilitate consultation with public parties to develop a management plan applicable to all stakeholders, and encouraging their collaboration

C SIC2 - produce a guidance plan for implementation of all conservation/archaeological/ development works to ensure they are appropriate and coordinated (enabling collaboration between the stakeholders involved within these initiatives) SIC3 - develop a master plan including zoned areas for various activities (enabling collaboration between the stakeholders involved within these initiatives, and following 'guidance plan' outlined in action SIC2)

E No proposed actions

Local cultural dynamic addressed: Conservation knowledge and awareness (CKA)

$\mathrm{G} \quad$ No proposed actions

I No proposed actions

C CKA1 - produce a guidance plan for implementation of all conservation/ archaeological/development works to ensure they are appropriate and coordinated (providing information to increase awareness amongst stakeholders involved within these initiatives) events and activities No proposed actions

Table 4. Activity 2: Stakeholder group actions addressing local cultural dynamics impacting Suakin's conservation (continued on next page)
Imminent

Imminent

Imminent

Imminent

Imminent

Imminent

Long term/ongoing

Imminent

Imminent/short term

Medium term

Short term

Imminent

Medium term

Imminent

Imminent 
Local cultural dynamic addressed: Response to the local context (RLC)

$\mathrm{G} \quad$ No proposed actions

I RLC1 - increase awareness of Suakin's conservation and the local context that must be Long term/ongoing

responded to by conservation initiatives

I RLC2 - consider Suakin's historic appearance and ongoing socio-cultural activities in future Long term/ongoing developments

C No proposed actions

E $\quad$ RLC3 - same as RLC2

E RLC4 - engage Suakin's whole/surrounding area and all stakeholders in future efforts and Long term/ongoing potential benefits

Local cultural dynamic addressed: political and legislative support (PLS)

G PLS1: enforce legal regulations that enable/specify the roles and responsibilities of

Medium-long term conservation actors, ensuring a relationship to reduce the contrast between them

I No proposed actions

C No proposed actions

E No proposed actions

${ }^{\mathrm{a}} \mathrm{G}$, government; I, investors; C, consultants; E, end users

Table 4. Continued

fewer specified actions. Although individually addressed, the relativity between the local cultural dynamics was revealed throughout the actions suggested to address them, such as

increasing stakeholders' awareness suggested to address FR, CKA and RLC

- legislative and formal planning measures suggested to address O, SIC, CKA and PLS.

Reinforcing these recurrent themes, suggesting the relative impact between local cultural dynamics, was a number of direct statements by the stakeholders. For example, the suggestion that FR would be resolved as a result of first addressing the other local cultural dynamics impacting Suakin's conservation, and a lack of CKA explained as a major contributing factor to inadequate SIC. Therefore, actions addressing CKA also addressed SIC.

\subsection{Activity 3: Identifying Suakin's cultural values}

Table 5 illustrates the stakeholder groups' ranking in order of importance or significance (the most significant being listed first) of Suakin's cultural values determined during activity 3 . This followed a brief presentation made on cultural heritage 'values' and conservation by a Unesco World Heritage Centre consultant. The results illustrated in Table 5 were categorised into the two major themes of tangible and intangible, and within these a number of sub-themes.

The stakeholder group presentations at the end of activity 3, and as shown in Table 5, revealed an initial general focus on
Suakin's tangible values. Suakin's intangible values also received the highest ranking by all of the stakeholder groups apart from investors, who recognised only Suakin's tangible values. Yet intangible values, despite their lower ranking compared to tangible values, occupied the majority of the discussion during activity 3. This was especially apparent among the end users, and demonstrated the direct link these values had to their everyday lives and subsequent relationship with Suakin and its conservation. Reinforcing this major focus on intangible values were the common values shared by all stakeholder groups as 'historical significance' and 'living culture', both intangible.

\subsection{Plenary session}

During the concluding plenary session there were no further questions or prevailing remarks raised concerning the previous workshop activities. The discussion instead focused on how to progress towards implementation of the suggested actions to address Suakin's conservation. It was proposed that the actions identified be developed into a formal management system for both Suakin's conservation and development through

formal legislative and planning measures

ongoing consultation

collaborative efforts between stakeholders.

It was also suggested that this management system be submitted as a key document in Suakin's application for World Heritage status. To ensure effective implementation of the suggested 
Stakeholder groups' ranked recognition of cultural values $^{a}$

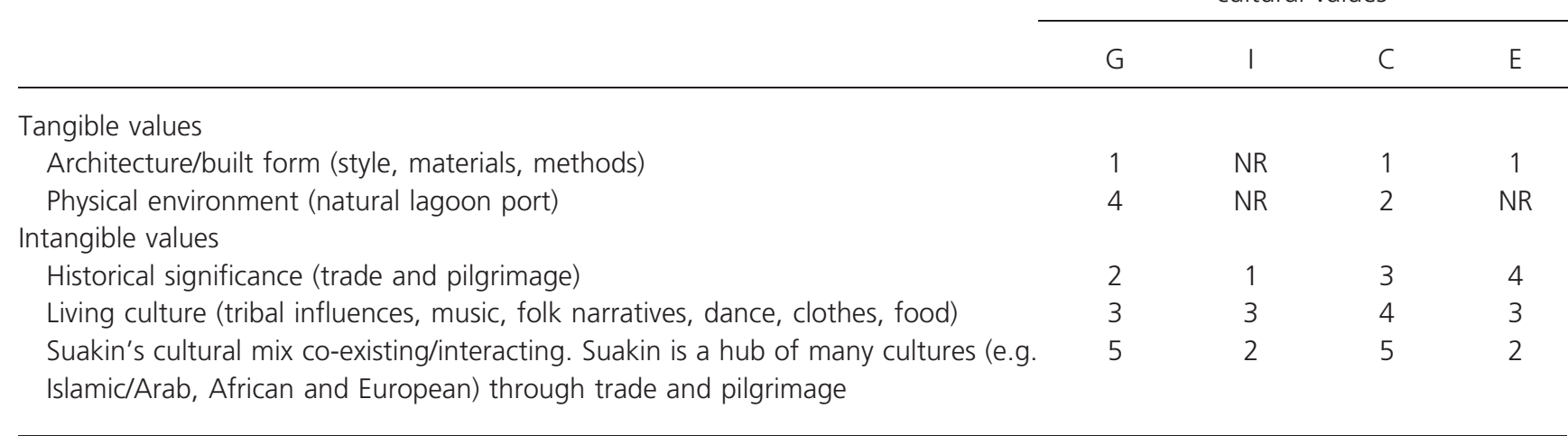

${ }^{a} N R$ : No recognition of cultural value by stakeholder group

Table 5. Stakeholder group perspectives on Suakin's cultural values

actions and formal recognition of the intended management system, many participants emphasised the importance of having key government officials present at future events.

\section{Discussion}

The workshop activities enabled stakeholders to rank in order of significance the major local cultural dynamics impacting Suakin's conservation, both individually and collectively within their stakeholder groups. The collective results of these activities revealed financial restrictions and ownership as the first two major local cultural dynamics impacting Suakin's conservation, and stakeholder inclusion and collaboration as the third. Conservation knowledge and awareness, response to the local context, and political and legislative support received varied rankings by the individual stakeholder and stakeholder group activities as the fourth, fifth and sixth local cultural dynamics impacting on Suakin's conservation.

A total of 16 actions and corresponding timescales to address these dynamics were then determined within the stakeholder groups, with each group addressing their top three ranked dynamics. The relative impact between local cultural dynamics and determined actions to address them was emphasised throughout the activity results. A major focus on the local living culture - and the need for Suakin's conservation to respond to this - was revealed throughout the actions proposed to address local cultural dynamics and the identification of Suakin's cultural values within the stakeholder groups.

Previous research has already established the impact of a number of the dynamics explored during this research on Suakin's conservation, such as ownership (Lane, 1994; Salim, 1997) and financial restrictions (Hansen, 1973; Salim, 1997). However, the structure and implementation of the workshop activities conducted for this research enabled a shared understanding among stakeholders and included the stakeholders themselves as an integral part of the research. This resulted in their collective responsibility to achieve the actions specified throughout the workshop activities and expressed during the workshop's plenary session towards Suakin's conservation to

- enable stakeholders to contribute towards Suakin's conservation through increased awareness and participation

implement suggested actions through formal legislative and planning measures.

These findings reinforce the need acknowledged in previous research to address the living cultural context of conservation (Chapagain, 2008; Zancheti and Kulikauskas, 2007) and for a collaborative stakeholder approach (Aas et al., 2005; Zancheti and Hidaka, 2011). However, there is little evidence of this being successfully achieved within the specific context of Suakin. Previous efforts have indeed attempted to join Suakin's stakeholders together in the formation of stakeholder committees (Salim, 1997) and a workshop event concerning the Suakin development plan (NCAM, 2007), yet neither of these attempts included the stakeholders within the design of the research being conducted or in future intentions resulting from the data obtained. The outcomes generated through previous efforts thus lacked a collective stakeholder understanding and input towards Suakin's conservation, which is vital to generate shared goals and a collective responsibility towards future action (Grosz and Hunsberger, 2006; Perkin, 2010) and which was addressed in this research.

\section{Conclusion}

This research aimed to explore the impact of local cultural dynamics on the conservation of the built heritage of Suakin 
Engineering Sustainability

Volume 167 Issue ES6
Impact of cultural dynamics on

conservation of Suakin, Sudan

Ashley, Osmani, Emmitt, Mallinson

and Mallinson through a collaborative stakeholder approach. The workshop activities resulted in the ranking of local cultural dynamics impacting Suakin's conservation, a number of actions to address these and identification of Suakin's cultural values, collectively determined by the stakeholder participants. The workshop activities began to generate the communicative structure necessary to encourage Suakin's stakeholders to work together. This enabled a collaborative process between the stakeholders through a shared understanding and collective commitment towards further action. There is no evidence that such inclusion and collaborative participation of Suakin's stakeholders has previously been achieved, and it has been demonstrated throughout this research that this is essential to progress Suakin's conservation effectively. As suggested by the stakeholders, their determined actions need to be implemented through formal legislative and planning measures, working towards a formal management system for Suakin's conservation. These efforts should be facilitated through a protocol that addresses Suakin's local culture, ensuring a comprehensive and inclusive approach with equal representation and participation of Suakin's stakeholders throughout future initiatives.

\section{Acknowledgements}

This research was funded by the EPSRC (Engineering and Physical Sciences Research Council). The workshop event conducted for the research was enabled through financial support by the Unesco Arab Regional Centre for World Heritage and was conducted in collaboration with Mallinson Architects \& Engineers and Sudan's National Corporation for Antiquities and Museums towards the future registration of Suakin as a World Heritage site. The authors acknowledge the support of the local Suakin community and all the participating stakeholders who made this research possible.

\section{REFERENCES}

Aas C, Fletcher J and Ladkin A (2005) Stakeholder collaboration and heritage management. Annals of Tourism Research 32(1): 28-48.

Araoz G (2011) Preserving heritage places under a new paradigm. Journal of Cultural Heritage Management and Sustainable Development 1(1): 55-60.

Bergold J and Thomas S (2012) Participatory research methods: a methodological approach in motion. Forum: Qualitative Social Research 13(1): Art. 30. See http:nbn-resolving.de/ urn:nbn:de:0114-fqs1201304 (accessed 11/11/2013).

Borg M, Karisson B, Kim HS and McCormack B (2012) Opening up for many voices in knowledge construction. Forum: Qualitative Social Research 13(1): Art. 1. See http://nbnresolving.de/urn:nbn:de:0114-fqs120117 (accessed 11/11/ 2013).

Bott AL, Grabowski S and Wearing S (2011) Stakeholder collaboration in a prospective World Heritage area: the case of Kokoda and the Owen Stanley ranges. Cosmopolitan Civil Societies Journal 3(2): 35-54.
Breen C (2007) Advocacy, international development and World Heritage Sites in sub-Saharan Africa. World Archaeology 39(3): 355-370.

Chapagain NK (2008) Towards rethinking conservation for traditional and vernacular architecture. Proceedings of 5 th International Conference of the Center for the Study of Architecture in the Arab Region (CSAAR): Responsibilities and Opportunities in Architectural Conservation: Theory, Education, and Practice, Amman, Jordan. CSAAR, Amman, pp. 355-365.

Chirikure S, Manyangab M, Ndoroc W and Pwitid G (2010) Unfulfilled promises? Heritage management and community participation at some of Africa's cultural heritage sites. International Journal of Heritage Studies 16(1-2): 30-44.

Daher RF (2005) Urban regeneration/heritage tourism endeavours: the case of Salt, Jordan - local actors, international donors, and the state. International Journal of Heritage Studies 11(4): 289-308.

Denzin NK and Lincoln YS (2000) Handbook of Qualitative Research, 2 edn. SAGE Publications, London, UK.

Dover G (2008) Scaling Up: Large Scale Participatory Projects. See http://participaction.wordpress.com/2008/07/15/scale/ (accessed 11/11/2013).

Fahmi W and Sutton K (2010) Reclaiming Cairo's downtown district - contesting the nineteenth and early twentiethcentury European quarter. International Development Planning Review 32(2): 93-118.

Gilbert M (2009) Shared intention and personal intentions. Philosophical Studies 144(1): 167-187.

Greenlaw J (1995) The Coral Buildings of Suakin. Kegan Paul International, London, UK.

Grimwade G and Carter B (2000) Managing small heritage sites with interpretation and community involvement. International Journal of Heritage Studies 6(1): 33-48.

Grosz BJ and Hunsberger L (2006) The dynamics of intention in collaborative activity. Cognitive Systems Research 7(2-3): 259-272.

Hansen E (1973) Preservation of Suakin. Unesco, Paris, France, Consultancy report 2970/RMO.RD/CLP.

Henderson JC (2008) Managing urban ethnic heritage: little India in Singapore. International Journal of Heritage Studies 14(4): 332-346.

Hill L (2011) Indigenous culture: both malleable and valuable. Journal of Cultural Heritage Management and Sustainable Development 1(2): 122-134.

Icomos (International Council of Monuments and Sites) (2000) The Burra Charter: The Australia ICOMOS Charter for Places of Cultural Significance 1999 With Associated Guidelines and Code on the Ethics of Co-existence. Icomos, Burwood, VIC, Australia.

Jokilehto J (2006) Considerations on authenticity and integrity in World Heritage context. City \& Time 2(1): 1-16. See http://www.ct.ceci-br.org (accessed 21/11/2012). 
Jokilehto J (2011) World Heritage: observations on decisions related to cultural heritage. Journal of Cultural Heritage Management and Sustainable Development 1(1): 61-74.

Kindon SL, Pain R and Kesby M (eds) (2007) Participatory Action Research Approaches and Methods: Connecting People, Participation and Places. Routledge, Abingdon, UK.

Lamei S (2005) Insights into current conservation practices. Museum International 57(1-2): 136-141.

Lane B (1994) Suakin Mission Report. Unesco, Paris, France, Consultancy report.

Lisitzin K (2005) Building shared perspectives in heritage management. City \& Time 1(3): 29-36.

Mallinson M (2012) Nominating Suakin as World Heritage site. In The History of the Peoples of the Eastern Desert (Barnard H and Duistermaat K (eds)). Cotsen Institute of Archaeology Press, Los Angeles, CA, USA, pp. 372-379.

McIntyre A (2008) Participatory Action Research. Sage Publications, Los Angeles, CA, USA.

Nasser N (2003) Planning for urban heritage places: reconciling conservation, tourism, and sustainable development. Journal of Planning Literature 17(4): 467-479.

NCAM (National Corporation for Antiquities and Museums) (2007) Suakin Development Workshop Unpublished Report. Suakin Development Workshop, Port Sudan, 7 December 2007.

Orbasli A (2008) Architectural Conservation. Blackwell Science, Oxford, UK.

Pain R, Whitman G and Milledge D (2012) Participatory Action Research Toolkit: An Introduction to Using PAR as an Approach to Learning, Research and Action. Lune Rivers Trust, Durham, UK.

Perkin C (2010) Beyond the rhetoric: negotiating the politics and realising the potential of community-driven heritage engagement. International Journal of Heritage Studies 16(1-2): 107-122.

Predota E (2009) Spotlight on participatory action research approaches and methods. Geography 94(3): 223-5.

Roders AP and van Oers R (2011) Editorial: bridging cultural heritage and sustainable development. Journal of Cultural
Heritage Management and Sustainable Development 1(1): $5-14$.

Rössler M (2010) World Heritage and cultural heritage management: new conservation challenges. Paper Presented at XVth International Summer University at ISES, Köszeg, Hungary.

Rypkema DD (2008) Heritage conservation and the local economy. Global Urban Development Magazine 4(1). See http://www.globalurban.org/GUDMag08Vol4Iss1/ Rypkema.htm (accessed 12/08/2013).

Saouma-Forero G (2006) Africa 2009: a story of African empowerment. Museum International 58(1-2): 83-94.

Salim AR (1997) Suakin: on reviving an ancient Red Sea port city. Traditional Dwellings and Settlements Review 8(2): 63-74.

Silverman RM, Henry L, Taylor JR and Crawford C (2008) The role of citizen participation and action research principles in Main Street revitalisation: an analysis of a local planning project. Action Research 6(1): 69-93.

Tomasello M and Carpenter M (2007) Shared intentionality. Developmental Science 10(1): 121-125.

Unesco (1972) Convention Concerning the Protection of the World Cultural and Natural Heritage Adopted by the General Conference at its Seventeenth Session. Unesco, Paris, France.

Unesco (2008) The Operational Guidelines for the Implementation of the World Heritage Convention. See http://whc.unesco.org/en/guidelines/ (accessed 14/10/2014).

Wadsworth Y (1998) What is participatory action research? Action Research International, Paper 2. See http://www.scu. edu.au/schools/gem/ar/ari/p-ywadsworth98.html (accessed 29/11/2013).

Zancheti S and Hidaka L (2011) Measuring urban heritage conservation: theory and structure (part 1). Journal of Cultural Heritage Management and Sustainable Development 1(2): 96-108.

Zancheti S and Kulikauskas P (2007) Introduction: changing role and relevance of urban conservation charters. City \& Time 3(2): i-i.

\section{WHAT DO YOU THINK?}

To discuss this paper, please email up to 500 words to the editor at journals@ice.org.uk. Your contribution will be forwarded to the author(s) for a reply and, if considered appropriate by the editorial panel, will be published as discussion in a future issue of the journal.

Proceedings journals rely entirely on contributions sent in by civil engineering professionals, academics and students. Papers should be 2000-5000 words long (briefing papers should be 1000-2000 words long), with adequate illustrations and references. You can submit your paper online via www.icevirtuallibrary.com/content/journals, where you will also find detailed author guidelines. 